\title{
E-Government Strategies in Spanish Local Governments
}

\author{
JOSE MANUEL RUANO DE LA FUENTE \\ Faculty of Political Sciences and Sociology, Complutense University of Madrid, Spain
}

\begin{abstract}
Interest in the use of new technologies as an instrument for the modernisation of public management is something common in public administrations. Local governments have recently invested considerable human and material resources to try to deliver services in a more efficient way. Although the progress made in the implementation of information and communication technology (ICT) has been significant, an analysis of all local government shows that its impact on the reform policies has been unequal, and that the real objectives of these processes of modernisation have not always been the same. Most governments have chosen a strategy that reproduces the way that the traditional administration works; whereas only a few have tried to make use of the potential that ICT offers to provide more transparency, new online services and to make administrations more receptive to citizens' needs. The first section of this article gives global data about the development of ICT in Spanish municipalities. Next, the websites of Spanish cities are analysed to identify the factors that enhance e-government and its implementation in the benefit of transparency, interaction with citizens and accountability.
\end{abstract}

KEY WORDS: E-government, e-governance, transparency, accountability

\section{Introduction}

During the 1980s, the modernisation of public management was identified with the search for efficiency, effectiveness and productivity in public services. However, in recent years public administrations have tried to increase citizens' trust in the public sector by improving the quality of services, orienting themselves to citizens' needs and enhancing transparency and accountability.

The confluence of policies based on New Public Management (NPM) methodologies, the rapid expansion of new technologies and the search for new forms of governance are factors that have favoured the emergence of e-government. The objective has generally been to use information and communication technologies (ICT) as an instrument to transform public administration by making it more efficient, transparent, accountable and receptive to social problems and citizens' demands.

Correspondence Address: Professor José M. Ruano, Complutense University of Madrid, Department of Political and Administrative Sciences, Faculty of Political Sciences and Sociology, Campus of Somosaguas, Pozuelo de Alarcón, Madrid 28223, Spain. Email: jmruanof@cps.ucm.es 
But the implementation of e-government has resulted in the formulation of different e-government visions and strategies, driven by their own sets of economic, political or institutional factors and requirements. The missions and objectives incorporated in these e-government strategies have focused on a variety of goals: from online service delivery to the modernisation of public administration; from efficiency improvement to more comprehensive perspectives (that include, for example, issues such as e-democracy and citizen engagement).

Technological change has impacted on the management of both public and private organisations. Public administrations have been forced to change their structures and ways of working as a consequence of the adoption of ICT. The flexibility provided by the internet to access products, services and information has meant that citizens expect a greater degree of receptiveness in many contexts, but specifically in the relationships between them and governmental agencies. Therefore, technology has become key to improving the way the public sector undertakes its activities and delivers its services to citizens (Hughes 2003, Brown 2005). In the framework of NPM, ICTs play a central role in achieving the aims of increased efficiency, effectiveness and transparency, as well as providing a tool to promote accountability and citizen participation. ICTs therefore have the potential to radically change management practices and the organisational culture of public administrations.

In this sense, e-government is a key component in the processes of reform, modernisation and improvement of the public sector. It is common to refer to the concept 'governance in the digital age' to describe all the reforms made in public management based on the use of ICT. Some authors (Chadwick and May 2003, Duivenboden and Lips 2005, Homburg and Bekkers 2005) have supported the idea that NPM and e-government are closely linked reform movements, and that e-government simply strengthens the process of management change initiated by NPM. This idea would explain the fact that the implementation of ICT by public administrations is taking a new turn in favour of efficiency and effectiveness in service delivery.

With this idea in mind, and taking into account the fact that reforms in the public sector in recent decades have pursued different objectives (for example, the development of public services, the improvement in accountability, and/or the promotion of citizen participation) in order to increase the administration's legitimacy (Pollit and Bouckaert 2000, Hernes 2005), this article seeks to identify the e-government strategy of Spanish local governments.

\section{The role of ICT in the reform of local governance}

Unlike in the initial stages of the NPM reform movement, the current initiatives to promote the openness and accountability of public administrations have nothing to do with concerns about efficiency in the public sector; but rather with the profound changes in the Organisation for Economic Co-operation and 
Development (OECD) countries that represent the effort of public administrations to respond to new social challenges (Matheson 2004).

Therefore, the drive for reform in public management is not only aimed at efficient service provision, but the need to address citizens' changing needs and their decreasing trust in public institutions. In this sense, e-government is the last step in an evolutionary process that will eventually qualify citizens to fully participate in decision-making. In this sense, the internet can be viewed as an instrument to support the achievement of good governance through increased transparency and the greater responsiveness of services to citizens' social demands. According to Clift (2003), e-government aims at five objectives: improving governmental decisions, increasing citizens' confidence in public administration, achieving better transparency and accountability of public organisations, taking into account citizen demands, and enabling the active involvement of all social agents to solve social problems. In consequence, e-government offers new opportunities to improve governance. The interactive nature of the internet, together with its capacity to accelerate communications, means it has the potential to make the process of governance work better than in the past.

According to Moon (2003), ICT can help governments re-establish citizens' trust in public institutions by improving transparency, efficiency, effectiveness and political participation. Developing the same idea, West (2005) argues that the implementation of e-government in the long term should not only be seen as a revolution in terms of service delivery, but as a tool to improve citizens' control over public administrations.

Regarding the first strategic objective, responsiveness to citizens' needs, ICTs have had a remarkable influence on the relationships established between administrations and their users. The internet creates an open, round-the-clock and direct communication between citizens and an administration. This interactivity is precisely what allows an administration to be more receptive to citizens' demands and needs. Therefore, e-government is a revolution in the way that a public administration maintains contact with its citizens. E-government development is helping to foster the idea that citizens are clients and that their satisfaction is important. Internally, e-government aspires to transform structures, operations and management culture through effective cooperation and the integration of services and processes among different organisations and administrative organs in order to establish a more integrated administration for the final user. What has specifically changed is the acceptance that not all citizens are the same, and that only a responsive civil service is able to provide different kinds of services tailored to the different needs of the individual users. Users of public services are not, and should not be, experts on departmental boundaries. In the provision of services several organisations can collaborate, and e-government can contribute to the final product by bringing together all these entities in a common website, and by helping to overcome the traditional administrative boundaries. However this change will not come about automatically. Technology can help achieve this aim, but political will plays a core role. The internet is the essential instrument of online one-stop-shops. ICTs can be used as 
an additional aid for quality improvement initiatives. They can be employed as an instrument to learn about citizens' opinions about public services; as a tool to widely diffuse quality standards; and as a way to illustrate progress online, at a very low cost. Additionally ICTs can help promote more effective communication between civil servants; assist in the re-design of the organisation; or establish new ways of online training. However, the implementation of these kinds of initiatives to improve quality - like other innovations in public management reform - should be examined carefully before proceeding. The objective may be to improve public services and confidence in administration, or simply to implement various marketing strategies to show an image of modernity and a false interest in citizens' demands.

Improving citizens' trust in public institutions implies something more than simply providing better services in an agile way (Torres 2004). A modern administration must not only be efficient, but should also promote ideas on democratic participation and accountability. It should show an active interest in citizens' problems and engage in activities that influence their day-to-day lives (Keating 2001). As a consequence of this type of thinking, there have been a great variety of programmes and initiatives designed to guarantee a higher level of citizen participation. Increasingly, e-government is considered to be a useful tool that will permit the long-term transformation of the administration beyond service provision through the internet. ICTs (and especially the internet) promise to revolutionise the conditions of participation in the governance process because they supply general access to a higher level of information, and have the potential to improve the access of various social agents to information. Opening up decision-making processes can improve the quality of final decisions because of the fact that the active participation of stakeholders allows decision-makers to have a more in-depth knowledge about the impact and context of various alternative options. This is a key element to be considered in the implementation of ICT in public administrations, because the chance to have access to more information, and the possibility of maintaining contact, could lead to better-informed citizens who are more able to participate in democratic processes. However, these are only options that technology makes possible. Progress in ICT implementation is insufficient to achieve changes in governance systems.

Development of ICT has led to changes in the way information is exchanged, and has enhanced transparency in the governance processes. According to the OECD (2003), the growing capacity to share information has fostered transparency, but it has also increased pressure on administrations. ICT can supply more relevant information and force the administrative processes to be more open and democratic. Increased transparency in public management (providing information about, for example, who takes the decisions, what actions are carried out, which resources are consumed, as well as the results and impact the have measures had), can be key for citizens to feel that they have real control over their administration. Therefore, evolution towards e-government is considered to be a step forward towards greater accountability by citizens (Holzer et al. 2004).

On the other hand, it should not be forgotten that efficiency has been the main driving force behind most public management reform initiatives for more than 
two decades (Pollit 2000). Numerous empirical research studies have found that the implementation of ICTs have improved efficiency in the public sector (Danziger and Andersen 2002, Forlano 2004). Even simple task automation using new technologies has improved efficiency by reducing the utilisation of material and human resources.

Nevertheless, it is important to bear in mind that the existence and the use of technology is insufficient on its own to guarantee improved service provision. ICT, the internet and intranets can be used either to overcome traditional organisational cultures, or to strengthen them. Organisational change and active citizen participation are not an automatic product of new technologies; rather they can make the change easier and possible. E-government is simply an instrument to achieve more important objectives; it is not an aim in itself.

\section{E-government: its different meanings and levels of implementation}

The e-government concept includes heterogeneous elements and different dimensions. Some authors argue that e-government can combine different aims: for example, making administrations more transparent and accountable (Moon 2002). However, from a more narrow perspective, other authors consider that the use of ICT, and the internet especially, should be focused on delivering more efficient and effective public services. This limited vision of e-government identifies this phenomenon with the use of new technologies to automate processes directed at service delivery (West 2004, Marche and McNiven 2003, Reddick 2004, Carter and Bélanger 2005). The wider perspective of e-government links the use of new technologies either to the functioning of public administration and the models of service delivery (Homburg and Bekkers 2005, Bhatnagar 2004, Tambouris et al. 2001) or to the creation of new ways of citizen participation in public affairs (Allen et al. 2001, Roy 2005, Moon 2002, Asgarkhani 2005). Either way, both visions share the belief in e-government's capacity to transform public administration and its governance processes.

Differences in definitions are not superficial, since they reflect priorities in the strategies of management of public institutions. For the former group, e-government is defined as service delivery through the internet. For the latter, e-government is a tool that is capable of transforming public administration and its relations with citizens by using ICT. In this article we argue that e-government is not simply an instrument for citizens to interact electronically with government, but has also to do with the transformation of the basic relations between public administrations and the public in general (Wimmer 2003, Jaeger 2005, Saxena 2005). The reason for this is that the communicative and interactive capacities of the internet help to enhance transparency, accountability, citizens' trust in public institutions and the democratic process. E-government must aspire in consequence to go beyond the simple provision of information and online transactions.

The concept of electronic democracy creates new areas where citizens can be consulted and can periodically express their demands and preferences. The implementation of ICT implies therefore an acknowledgement that citizens' opinions are increasingly important in policy-making processes and can respond 
to demands for more transparency and participation. We agree with some authors' thinking (Michel 2005, Thomas and Streib 2005), who include consultation and communication initiatives through electronic methods as part of egovernment and reserve the term e-governance to refer to the most active mechanisms of participation in policy-making. In this sense, e-governance embodies two intertwined dimensions (Bhatnagar 2004): a political dimension (that includes accountability and political participation), and a technical one (linked to issues on efficiency and public management). Therefore, e-governance has a wider meaning than e-government, because it is bound to e-governance's technical dimension.

Moreover, at an external level, technologies based on the internet can facilitate collaboration between government agencies, private companies and citizens - in service delivery and/or political activities. Websites and email are considered to be essential vehicles to improve cooperative working between administration and civil society. There is however a broad consensus on the idea that different stages can be distinguished in the implementation of e-government's initiatives, depending on the degree of development achieved (Moon 2002, Criado and Ramilo 2003, West 2004, Siau and Long 2005). The diffusion of information, or the possibility of downloading forms through the website, represent the most basic level of implementation. Bi-directional communication between administration and user, online service delivery or citizen participation in policy-making would be some examples of highly developed e-government. However, these possibilities should not be understood as consecutive stages in the process of e-government implementation, since public institutions can work on specific phases to achieve immediate results, or can deliver some services that have different levels of development, or can be interested in developing some elements of online services or electronic democracy at different speeds.

In the framework of this research, three levels of e-government development have been considered. Level I includes single-way information from the administration to the citizen: for example, general information about the municipality and its organisation, or about procedures and the possibility of downloading documents and application forms. Level II is characterised by the fact that ICTs are used to create a new channel of communication between citizen and administration. This stage of interaction can be seen as the first step towards the setting up of transactional pages. At this level, users have the capacity to complete online transactions, send forms electronically and make payments to public institutions. In this way, delivery and comprehensive management of services through the internet is affordable: renewal of licenses, tax or fine payments, application of social benefits, and so on. At this stage the administration seeks to integrate several services in a horizontal way (different organs of the same government) or in a vertical one (between different levels of government). The final goal of this stage is to guarantee service provision based on the concept of a 'one-stop-shop' or 'integrated service delivery' (Kernaghan 2005). This latter concept refers to an integration of public administration that allows citizens to access services - not simply because they are familiar with the organisational 
structures of the administration, but on the basis of their needs. However the achievement of this goal requires more process coordination and more organisations working together.

Finally, level III of e-government implementation in this research refers to the use of ICT to enhance transparency in order to achieve more accountable administrations. We have specifically considered all the information that facilitates citizen control of the administration's performance: the existence of management indicators, data on public policies' results or impacts, financial and economic information, blogs of political representatives, budgetary information and any citizen consultation or participation mechanism.

The three theoretical criteria taken into account that have led to these levels of e-government development are the principles of information, interactivity and transparency, that correspond to levels of implementation I, II and III respectively. Transparency refers to the extent an organisation offers all the information about its structure in its website, internal divisions, procedures and decisionmaking processes, in an understandable way and adapted to the needs of the various kinds of users of public services. Transparency cannot only be considered a value in itself (Koppell 2005), but it should be at the service of accountability to increase the confidence of the public and, indirectly, the legitimacy of public institutions (Gant and Gant 2002). Interactivity allows the citizen to pass from being a passive subject to an active agent, endowed with rights, and capable of communicating with his/her administration to demand satisfactory and adequate responses to his/her specific needs. The combination of these principles should reflect the degree of openness of the institution, the way the administration delivers comprehensive information through its website, and how it keeps in touch with its end-users. Therefore, the degree of governmental openness can be understood as a measure of the administration's receptiveness to citizen's demands for information and services, and as a measure of accountability of public administrations.

\section{The use of ICT and its impact on Spanish local governments}

The legal framework for the use of ICT by Spanish local governments is Law 11/ 2007 on Electronic Access of Citizens to Public Services. This law is the juridical cornerstone for ICT implementation in public administrations since for the first time it recognises the 'right of citizens to come into contact with public administrations electronically' (art. 1.1). As a consequence, the development of e-government strategies cannot be limited to the use of ICT as an instrument of modernisation and improvement of internal efficiency, but as a tool that is going to condition and model the relations between the citizen and the administration; which necessarily implies the transformation of traditional ways of service delivery and the requirement to guarantee the security and confidentiality of the electronic transactions. All this means that for the first time administrations pass from an approach that depended on political will, to a compulsory system that requires respect for the prescriptions of the law; a change that is especially 
challenging for small local governments because of their low level of human and material resources.

From the user's point of view, the law allows citizens to maintain electronic relations with their administrations and to have electronic access to all the information that the administration has about them and about the procedures initiated by them. This kind of electronic relation aims to improve efficiency in service delivery and to simplify and make easier the defence of citizens' rights; but all this requires in turn improved cooperation between governments and administrative organs.

According to the Dossier of E-government Indicators (IRIA) report, published every two years by the High Council of Electronic Administration (which is responsible to the Ministry of Public Administrations and that has the role of analysing the presence of ICT in local governments), there has been a positive and steady trend in recent years towards greater investment in material and human resources linked to new technologies.

As can be observed in Figure 1, the rise of investment in local governments has been constant and has reached 751 million euros in 2007; which represents an increase of $19 \%$ compared to 2005 figures.

This increase in ICT investment is both for material resources and personnel. Figure 2 presents the number of existing computers in local governments, and Figure 3, the number of local public servants with access to an intranet and the internet.

The analysis of these global data, on the basis of the typology of municipalities and their population size, highlights some important differences:

First, average expenditure on ICT per inhabitant is 15.29 euros (see Figure 4); although this investment decreases as municipality size falls. The only exception

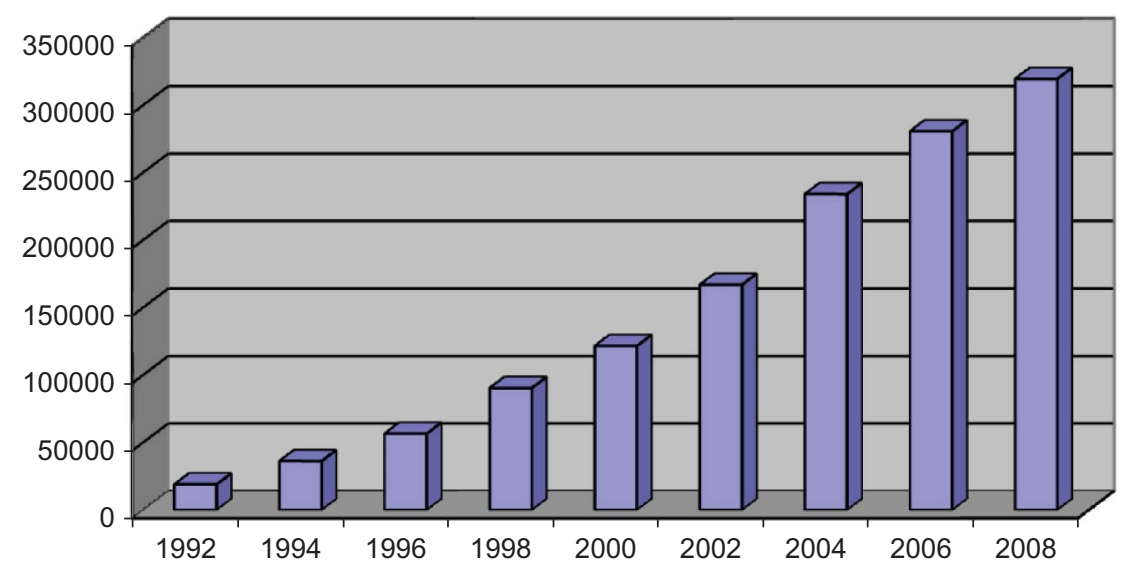

Figure 1. ICT expenditure. Evolution.

Source: Ministry for Public Administrations (2009). 


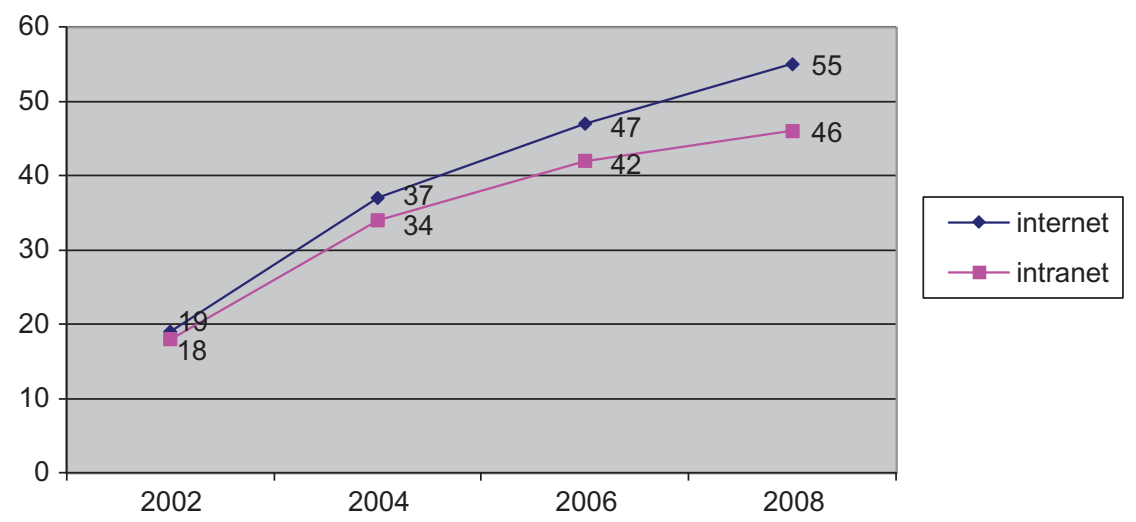

Figure 2. Number of computers. Evolution.

Source: Ministry for Public Administrations (2009).

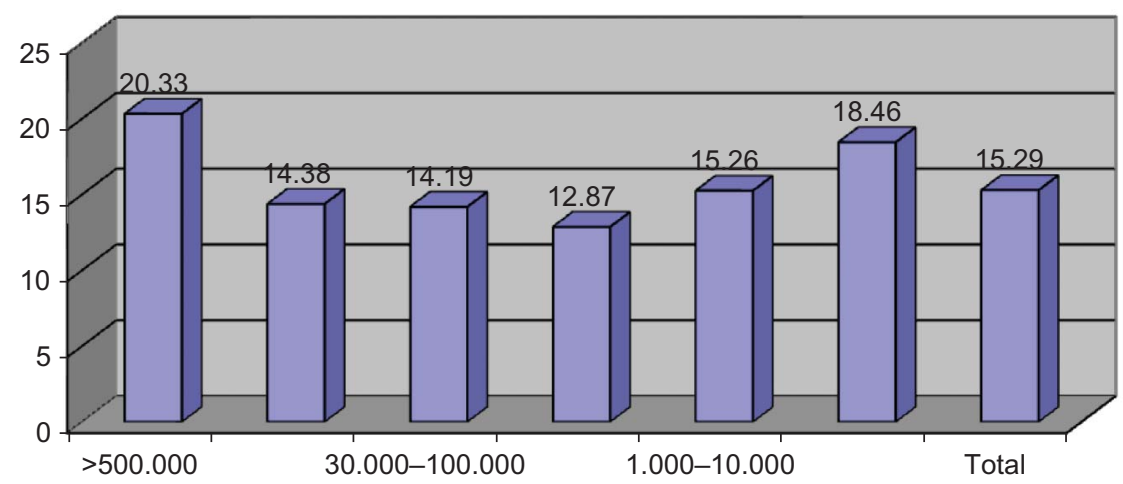

Figure 3. Percentage of employees with access to internet and intranet. Source: Ministry for Public Administrations (2009).

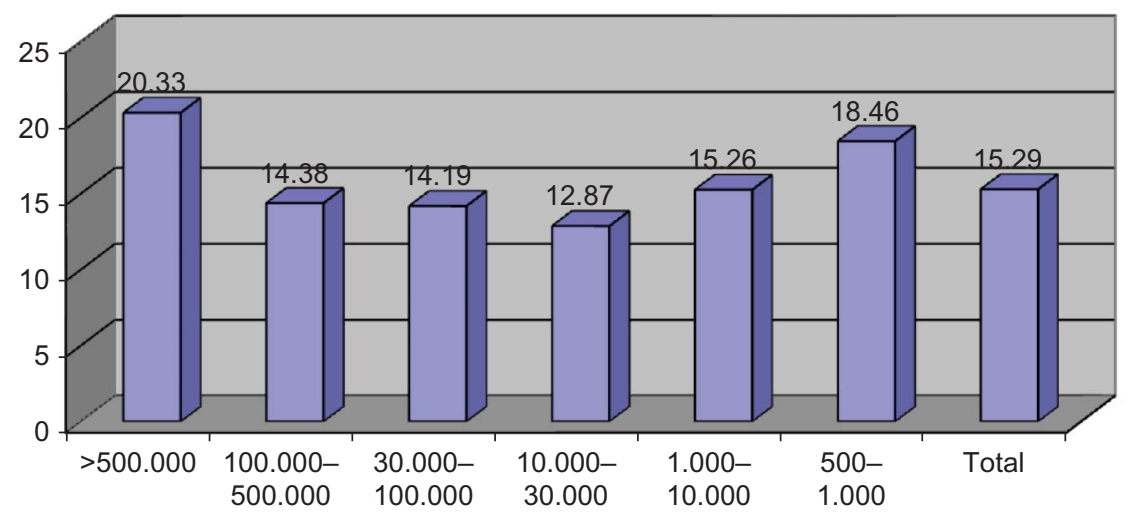

Figure 4. ICT expenditure (in euros)/inhabitant.

Source: Ministry for Public Administrations (2009). 
is municipalities with under 10,000 inhabitants, due to their extreme financial limitations that prevent them from benefiting from economies of scale.

As can be seen in Figure 5, expenditure in ICT in relation to the total budget is over the average in the municipalities with more than 500,000 inhabitants, and progressively decreases according to size. Again, we can confirm the budgetary limitations of small municipalities and, as a consequence, their difficulties in keeping up with the rhythm of big cities' investment in ICT.

As previously mentioned, the internet is one of the key instruments that local governments have to transform the way in which they make contact with citizens, and to modernise service delivery. An analysis of the percentage of local governments that are connected to the internet (Figure 5) or the local governments with a website (Figure 6) shows that a significant percentage of municipalities under 30,000 residents $(28 \%)$ do not have access; and this percentage dramatically increases in municipalities that have under 10,000 (71\%) and 1,000 (84\%) inhabitants. These entities are located in rural areas with very low population density.

From Figure 5 we can see that all public administrations in big cities have their own website; as do almost all municipalities with over 100,000 inhabitants. However, $28 \%$ of municipalities with under 10,000 inhabitants, and $50 \%$ that have under 1,000 inhabitants, do not have their own website. Furthermore a significant percentage of municipalities have a website linked to, and located in, the provincial government's web (39\% of municipalities under 10,000 inhabitants).

Following this quantitative analysis, it is necessary to undertake a qualitative analysis on its real usefulness: only $50 \%$ of large municipalities accept payments by credit card, and this percentage decreases notably in medium and small-sized municipalities (see Figure 7). Only local governments with over half a million inhabitants deliver a complete online service (see Figure 8), and many of the municipalities have websites that do not even fulfil the requirements and rules of

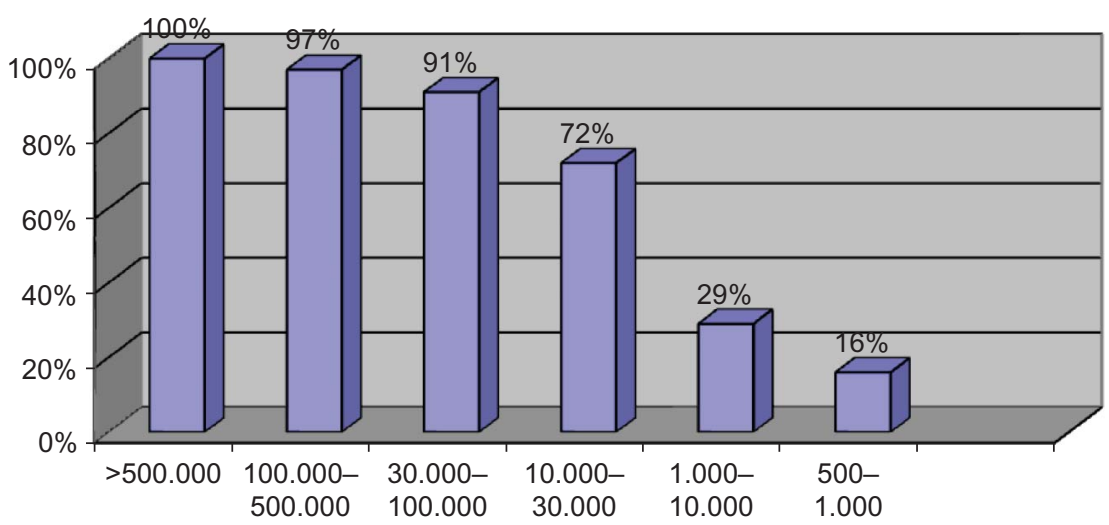

Figure 5. Local governments with access to the internet.

Source: Ministry for Public Administrations (2009). 


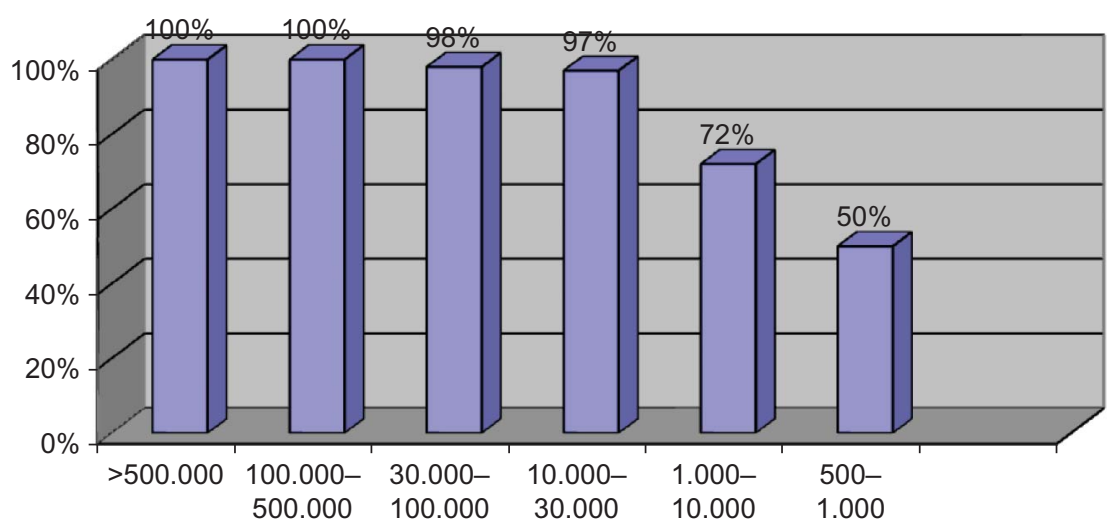

Figure 6. Local governments with website.

Source: Ministry for Public Administrations (2009).

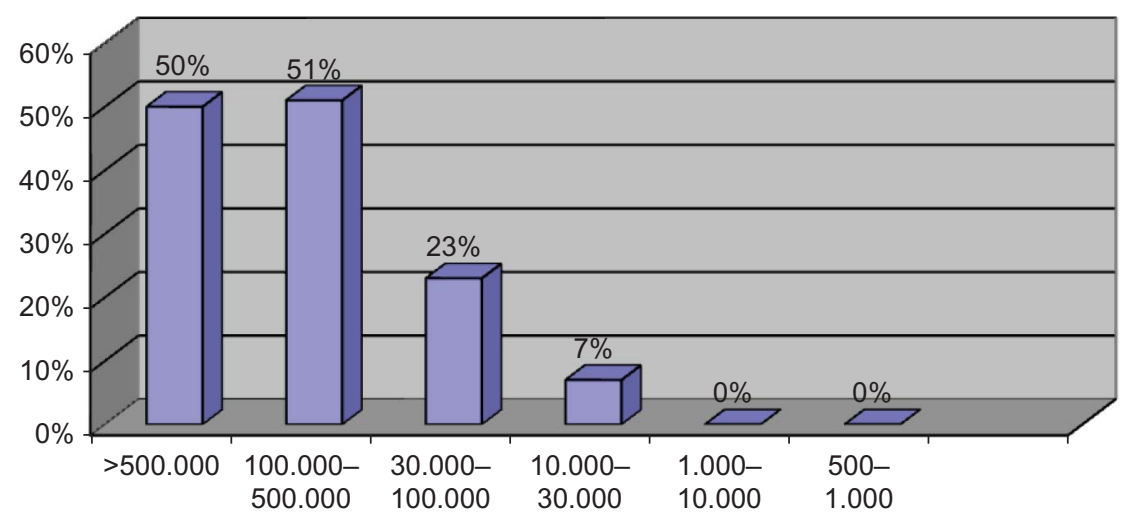

Figure 7. Local government websites that accept payments by credit card. Source: Ministry for Public Administrations (2009).

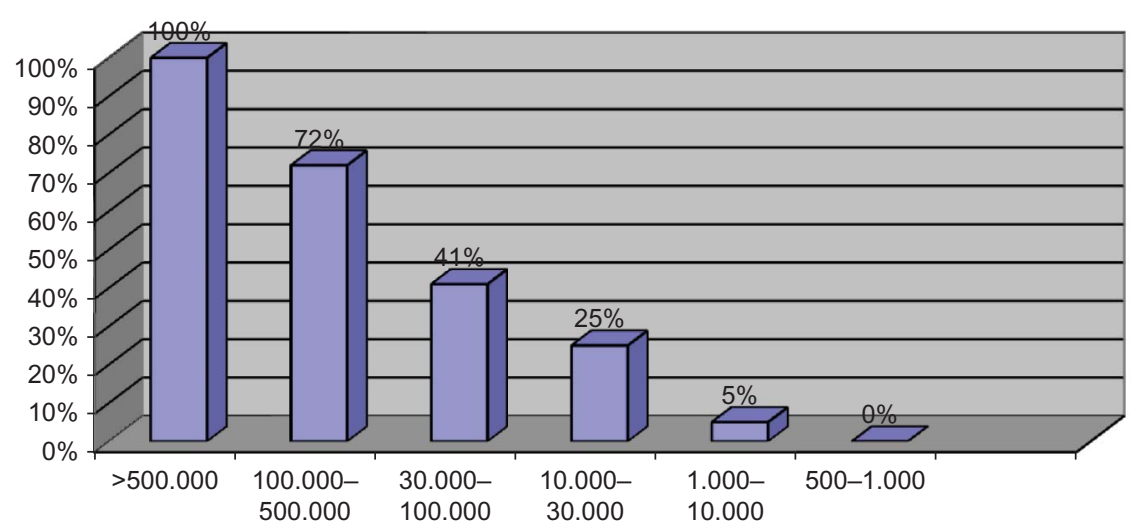

Figure 8. Websites that deliver online services completely.

Source: Ministry for Public Administrations (2009). 


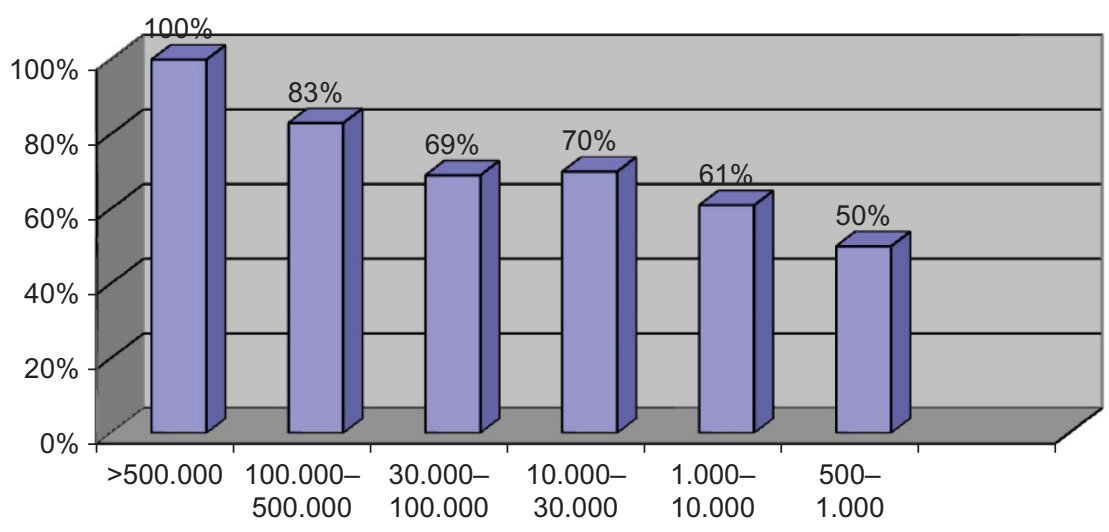

Figure 9. Websites that respect rules of accessibility. Source: Ministry for Public Administrations (2009).

accessibility required by law. It is surprising to find that only $50 \%$ of the smallest municipalities abide by this demand (see Figure 9).

A first conclusion from the analysis of these data is the existence of a direct relation between population size and e-government capacity. For this reason, a global e-government strategy should not only act at the local level, but should include initiatives that seek to spread ICT and the use of the internet in civil society, through the leadership of supra-municipal governments and/or by horizontal co-operation.

This relation between population size and e-government capacity has been confirmed by numerous research studies (Travers et al. 1993, Weare et al. 1999, Musso et al. 2000, Holden et al. 2003, Ho and Ni 2004, Justice et al. 2006, Royo 2008, Andrews and Boyne 2009), that have drawn on different theoretical approaches and various contexts. On the one hand, the greater the population (or clients) to be served by an organisation, the more intense will be the pressure on that organisation to deliver the services offered by other organisations (DiMaggio and Powell 1983, Ho and Ni 2004). A greater population also usually means the existence of more diversified demands and expectations on public services, and this results in more pressure to look for innovative ideas and programmes to satisfy the various needs of the citizens. Furthermore, cities have more incentives to improve their reputation and public image because of their higher external visibility (Debreceny et al. 2002). On the other hand, it is assumed that there is a positive correlation between organisation size and its capacity to innovate (Rogers 1983). The early implementation of public management reform policies is linked to administration needs, and can be predicted on the basis of the social and economic structure of the municipality and its size. However, DiMaggio and Powell (1983) bind innovation to the search for legitimacy, and not to municipality features. Additionally it should not be forgotten that another incentive to develop e-government is the cost decrease that can result from maintaining effective communication with a larger number of citizens. 
Furthermore, population size is considered to be an indicator of the level of resources of the organisation and of the existence of a more specialised and professionalised personnel. The areas with higher population density usually have more financial and human resources and this factor can lead to earlier e-government development. Therefore, the number of inhabitants can be a key factor since the greater the population, the less the average cost per user.

The positive correlation between population and e-government development is especially important in countries where most municipalities are very small; and that is the case for Spain, where $85 \%$ of local authorities have under 5,000 inhabitants and $60 \%$ under 1,000 . This is especially important precisely because most inhabitants of these rural areas are older people who are not familiar with new technologies. According to the report e-Spain 2011 (Fundación Orange 2011), produced by drawing on data from the National Institute of Statistics, barely $15.4 \%$ of the population who are between 65 and 75 years old frequently use a computer. It is clear that there is an inverse relationship between age and the use of the internet. The data from rural areas show that only $31.4 \%$ of homes have access to the internet. Many of these areas are characterised by very low population density and they lack basic infrastructure, such as essential telecommunication services. As in most countries of the European Union, it is possible to estimate a correlation between density of population and number of homes with access to the internet. The reason why the Spanish case is unique is the high percentage of rural municipalities and the heavy concentration of older people living in them. It seems that the digital gap because of age is reinforced by the deficit that these rural areas have in infrastructures and essential services.

\section{ICT in Spanish cities}

As we have seen above, larger municipalities offer better global results in e-government development because they have more economic, human and technical resources than the smaller ones. Now we present an analysis of the webpages of Spanish cities. We have analysed all cities with more than 75,000 inhabitants, or which are the capital of a province. These 93 municipalities represent the Spanish urban map.

In order to analyse the webpages, three levels of development have been distinguished, as were described in epigraph 2: first, we have taken into account all the single-way information that emanates from the administration to the citizen; level II is formed by all the instruments that allow bi-directional communication between citizen and administration; and finally, level III includes the possible existence of tools not directly linked with individual service delivery, but that allow the citizen to have a better knowledge of municipal management and to offer a higher degree of transparency on basic elements like the budget, management indicators, decisions taken by collegiate organs or mechanisms of communication between citizenship and people in office.

We already know that almost all of these municipalities have their own website. Furthermore, as can be seen in Figure 10, nearly all offer general information on the 


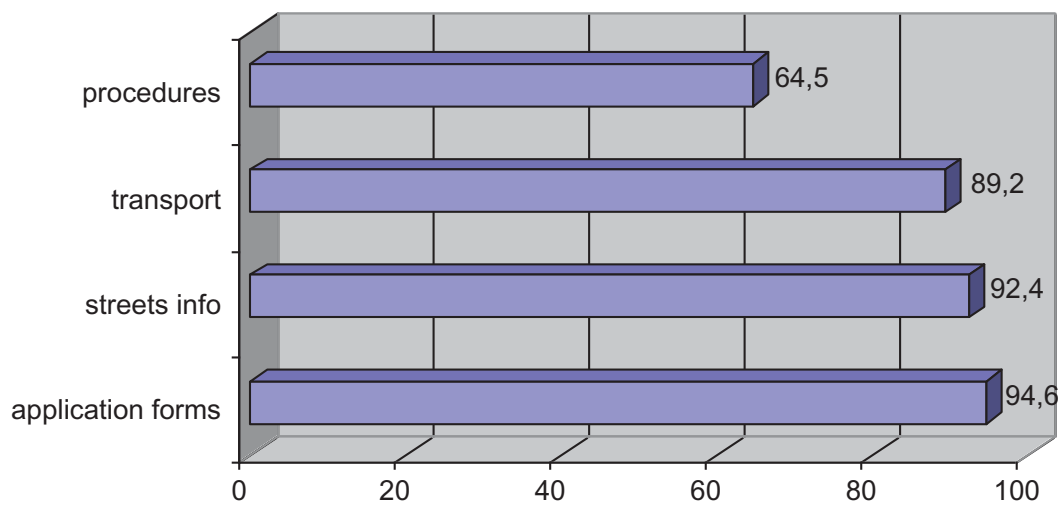

Figure 10. Information on the websites of large cities (level I).

municipality, its organisation, transport and streets; and they also provide the opportunity to download different kinds of documentation and application forms. In this respect, these websites function well as electronic noticeboards. However, only some websites deliver more sophisticated information, such as information about how to undertake specific procedures, or how to apply for certain services in the municipality.

As Figure 11 shows, if we analyse the effort at bi-directional communication made by local governments, the results are more disappointing. Almost all cities have email or a fixed telephone, but less than half allow payments by credit card, provide a mobile phone number, or allow citizens to monitor the electronic procedures initiated by them. It is also surprising that only around a quarter of them allow their citizens to initiate procedures through digital certification or a 'citizen folder' (that contains all the information about the transactions and communications between the citizen and the administration in order to make

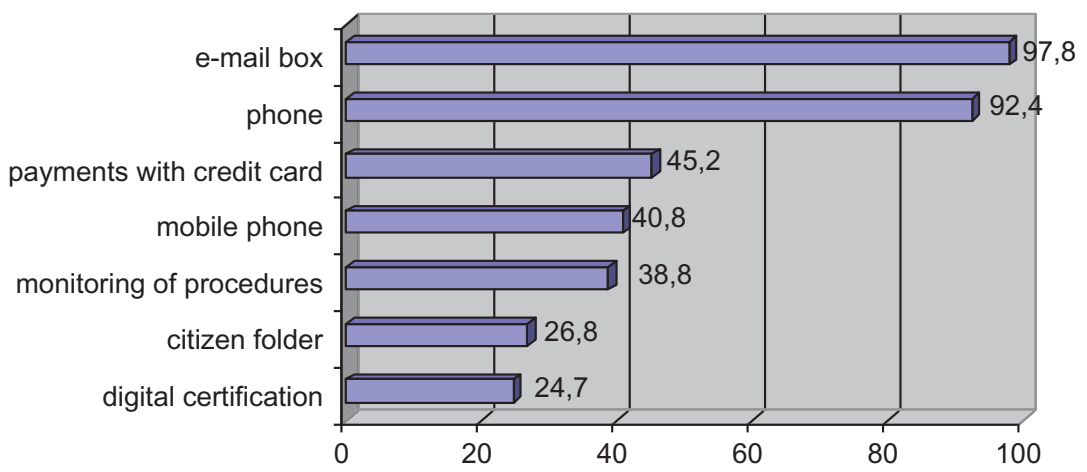

Figure 11. Interaction tools on the websites of large cities (level II). 
the relations easier and facilitate the personal communication). This is even more striking because the above-mentioned Law 11/2007 requires all local governments to develop and maintain an electronic registry, and to serve all citizens who want to use this channel.

In order to assess the quality of the information service, a question was sent to all the cities. The question asked how to register a new neighbour in the municipality, and the results were not very positive (see Figure 12): only 54 answers were received from the 93 cities requested (58\%). Furthermore, only 28 replies could be considered more or less satisfactory (in that they included a correct answer and indicated how to make the registration and where). However, the rest of the answers were unsatisfactory for various reasons: some said they did not know or it was not their issue; others attached the form where we could look for - and presumably find - the answer; while some asked us to forward the question to another institution, or forwarded us to another department within the same administration.

The first conclusion from this survey is that most of the analysed webpages have only attained a very low level of development and are not oriented to citizens' needs, and hardly any of them take advantage of all the possibilities that new technologies offer. In spite of the fact that almost all of the webpages put a large amount of information at the citizens' disposal, unidirectional information is predominant and the possibilities of interaction with citizens is reduced in practice to the use of email or the telephone; in this way merely strengthening the traditional bureaucratic styles and the dominant organisational culture.

Most of the cities analysed provide few services through the internet, or concentrate their efforts in very particular areas. Although the lack of material and human resources is a serious barrier for the rural municipalities, the same cannot be said about cities. Some of the obstacles for e-government development in this case have to do with resistance to change and incompatibility with an organisational culture

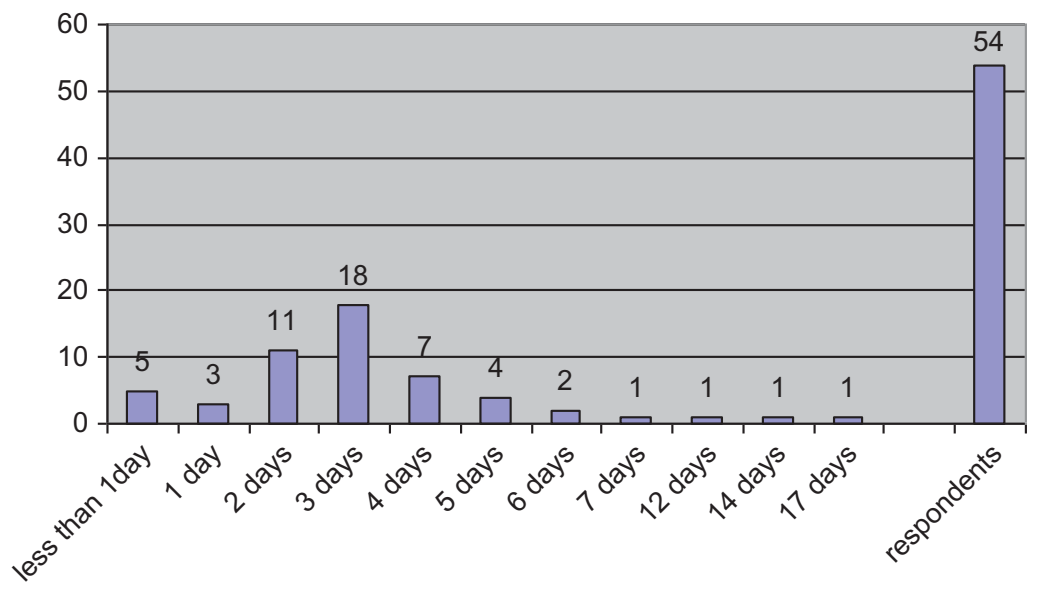

Figure 12. Responses from municipalities and speed in answering. 
that prevents an administration from giving more importance to citizens' needs or developing more accountable and transparent structures.

The study of Spanish local governments confirms that e-government is an increasingly significant issue and that nearly all of them have accepted the challenge of its implementation, although the level of actual development varies. Although webpages can offer some benefits related to administrative modernisation under the NPM approach, they have not achieved all the potential benefits for service delivery, provided sufficient information to the public or improved the way interaction between citizen and administration works. This statement is coherent with other research results (Musso et al. 2000, Taylor et al. 2001, Gant and Gant 2002, Criado and Ramilo 2003, Holzer et al. 2004), that have come to the conclusion that in nearly all the cities under study, e-government is an extension of the traditional administrative style and does not take best advantage of the opportunities offered by new technologies. Nevertheless, it has to be borne in mind that environmental factors (such as the administrative style, the development of the information age and the population size of the municipalities) can play a decisive role as a barrier or, on the contrary, as a facilitator.

We have seen that Spanish cities use their webpages as a channel to provide general information, reports, documents, legislation, proceedings, or to diffuse government decisions; and this result is positive in as far as all these data are more accessible. However, this new 'noticeboard' does not require the reform of current models of service delivery, and nor is it useful as a bi-directional channel of communication. The main aim seems to be that information is accessible through the internet; not that new ways of communication with the citizen are developed and enhanced. In any case, if citizens cannot make transactions with the administration through the internet, e-government will not alter the customary functioning of public administration and the way it traditionally delivers its services.

Naturally, interactivity development and online service delivery (level II of e-government) is costly and more consumes more effort than simply publishing information (level I), and this could partially explain the initial resistance to its implementation. Local governments seem to easily accept innovations, especially if they help to transmit an image of modernity and receptiveness to citizens' demands, and carry no obligation to make real changes in the way the administration works. This is particularly true if we look at the use of ICT to enhance citizen participation and accountability. E-government has barely been used as an instrument to engage citizens in the identification of social problems, or to include these problems on the agenda, or to evaluate them.

Spanish e-government predominantly seems to treat people as mere clients who obtain products and services from the administration, and less as citizens who have the right to participate and get involved in the decision-making processes that affect their lives. Local governments are even reluctant to publish the information that could be easily used to assess their performance properly, as Figure 13 shows.

It is clear that the internet can be an important tool to improve transparency and to diffuse information on government performance. This statement is supported by the empirical research that confirms the existence of successful cases in 


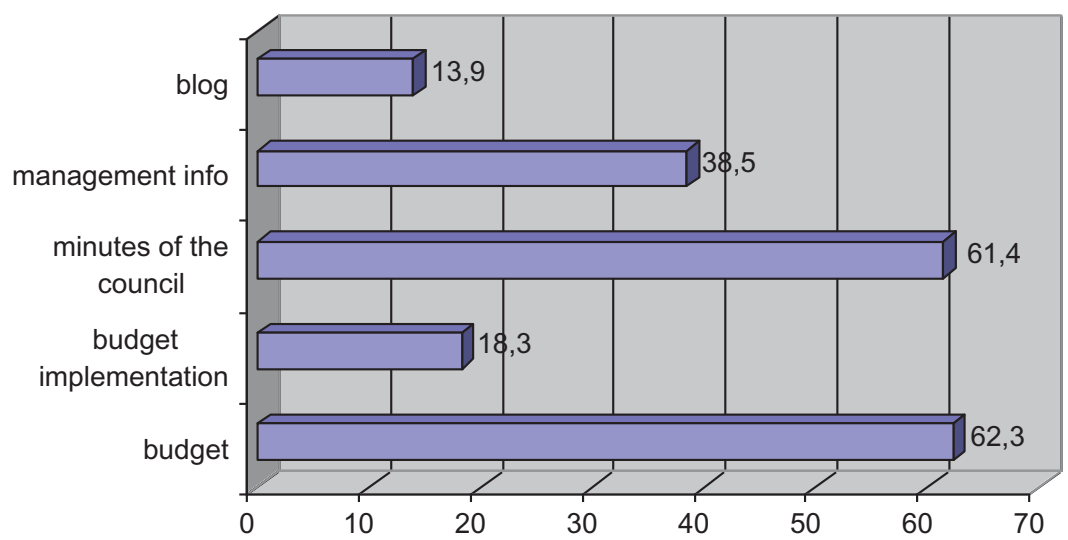

Figure 13. Accountability on the websites of large cities (level III).

both senses (Roy 2006, Wimmer 2007, Norris 2007, 2008, Chen et al. 2008, Reddick 2009) and professional networks (www.epractice.eu) that show and enhance the implementation of e-reforms. In spite of this evidence, in the case analysed the evident impulse to e-government has not led to significant progress in accountability. The information provided to citizens is to a large extent the budget passed for the current year and the minutes of the council, but it is much less frequent to find the implemented budget of the previous year or any other sort of management indicator. It is important to take into account that Spanish local governments are obliged to elaborate and publish this kind of budgetary information, and for this reason it is particularly surprising that they do not make use of their webpages to diffuse it. ICT can provide key information and make processes more open and democratic. This is why citizens should be allowed to supervise administration performance in a more rigorous manner.

However, in this case study, almost every local government was found to use their webpages to publish low amounts of budgetary information (normally comprising reduced versions of their reports published on paper). Therefore, at this point the advantages attributed to ICT seem too optimistic: at best, municipalities provide the same financial and budgetary information they are obliged to publish on paper, and very few offer management information or maintain blogs that allow citizens to get in touch with their political representatives. Webpages are instead used as an additional channel to spread political propaganda; rather than improving accountability processes or involving citizens in the dynamics of policy-making.

These deficiencies could partially be attributed to the existence of a rigid, bureaucratic and legalistic model of administration that has barely adapted itself to the reforms offered by NPM, and that has in general failed to transform the traditional way that the administration works. Real changes in accountability mechanisms depend to a great extent on domestic organisational and cultural factors. 
This statement shares with 'path dependency' theory the rejection of the idea that the same reform process will achieve similar results in any environment. Rather, the impact of the reforms will be influenced by particular environmental features, mostly inherited from the past; and in this way mere ICT implementation often simply reinforces existing practices instead of improving them, or offering greater innovation.

\section{Conclusions}

The pressure to improve efficiency and effectiveness in the public sector, and to increase citizens' trust in the administration, has led to the search for new methods of management that are more specifically oriented towards citizens' needs. It has also led to the need to improve the quality of public services, transparency, accountability and citizen participation in decision-making processes. In this search, ICT, and particularly the internet, have acquired special importance. ICTs on their own are not capable of contributing significantly to achieve these goals if their implementation is not accompanied with the real political will to empower citizens.

Local decision-makers give priority to the technical side of e-governance (improving efficiency, the quality of services, and administrative modernisation in general) over the political side (for example, accountability, citizen participation, and so on). There is a predominant vision of the citizen as a client of the services provided by the administration over the vision of the citizen who has the right to participate in the decision-making processes that influence their day-today life. A key feature of e-government strategies could be to reconnect the public with the administration. In a general context of political apathy, it is surprising that more efforts have not been channelled into greater interaction between citizen and government.

Nearly all Spanish local governments have begun to make use of new technologies to provide information through the internet, although most webpages offer a low level of interactivity with citizens and a limited degree of online service delivery.

Rural areas register 'the worst marks' in e-government development, due to difficulties in the affordability of internet access and the lack of human and material resources. These difficulties strengthen the digital gap phenomenon since these small municipalities are predominantly inhabited by older people.

The achievement of e-government goals requires that ICT are developed to a sufficient level to allow measurable changes to take place in the way government works and citizens are served. The ability of citizens to access ICT, the existent infrastructure, the affordability of internet access, the availability of basic ICT skills across society, the culture and the attitude towards ICT take-up, are only some of the factors that illustrate the impact of the local context on e-government strategy.

E-government development varies greatly depending on the municipality analysed. Cities achieve better results; but even in these cases transparency and accountability do not seem to be among their priorities. 
At a discursive level local politicians seem to be interested in the use of ICT in public administration and outwardly accept innovations; but in practice they turn away from any change that involves transforming their traditional way of functioning.

\section{Notes on contributor}

José M. Ruano de la Fuente is a professor in the Faculty of Political Sciences and Sociology at the Complutense University of Madrid (UCM), Spain, and has been a visiting scholar in several European and US universities. His research focuses on comparative public administration and local governance. He is vice-president of the Scientific Council of the European Association Entretiens Universitaires Réguliers pour l'Administration en Europe (EUROPA) and a member of the Permanent Study Group on Local Governance and Democracy in the European Group on Public Administration (EGPA).

\section{References}

Allen, B. et al., 2001. E-government and government online in Canada: partnerships, people and prospects. Government Information Quarterly, 18 (2), 93-104.

Andrews, R. and Boyne, G., 2009. Size, structure and administrative overheads: an empirical analysis of English local authorities. Urban Studies, 46 (4), 739-759.

Asgarkhani, M., 2005. The effectiveness of e-service in local government: a case study. The Electronic Journal of e-Government, 3 (4), 157-166.

Bhatnagar, S., 2004. E-government: from vision to implementation. New Delhi: Sage Publications.

Brown, D. 2005. Electronic government and public administration. International Review of Public Administration, 71 (2), 241-254.

Carter, L. and Bélanger, F., 2005. The utilization of e-government series: citizen trust, innovation and acceptance factors. Information Systems Journal, 15 (1), 5-26.

Chadwick, A. and May, C., 2003. Interaction between states and citizens in the age of the internet: e-government in the United States, Britain and the European Union. Governance: International Journal of Policy, Administration and Institutions, 16 (2), 271-300.

Chen, H. et al., eds, 2008. E-government research: case studies and implementation. New York: Springer Science Business Media.

Clift, S., 2003. E-democracy, e-governance and public network. Available from: http:// www.publicus.net.

Criado, J.I. and Ramilo, M.C., 2003. E-government in practice. An analysis of website orientation to the citizens in Spanish municipalities. The International Journal of Public Sector Management, 16 (3), 191-218.

Danziger, J.N. and Andersen, K.V., 2002. The impacts of information technology on public administration: an analysis of empirical research from the golden age of transformation. International Journal of Public Administration 25 (5), 591-627.

Debreceny, R., Gray, G.L. and Rahman, A., 2002. The determinants of internet financial reporting. Journal of Accounting and Public Policy, 21 (1), 47-74.

DiMaggio, P.J. and Powell, W.W., 1983. The iron cage revisited: institutional isomorphism and collective rationality in organizational fields. American Sociological Review, 48 (2), $147-160$.

Duivenboden, H. and Lips, M., 2005. Responsive e-government services: towards 'new' public management. In: V. Bekkers and V. Homburg, eds. The information ecology of e-government. Amsterdam: IOS Press, 141-154. 
Forlano, L., 2004. The emergence of digital government: international perspectives. In: A. Pavlichev and G.D. Garson, eds. Digital government: principles and best practices. Hershey, PA: Idea Group Publishing, 34-51.

Fundación Orange, 2001. E-Spain. Madrid. Available from: http:/fundacionorange.es/ fundacionorange/analisis/eespana/e_espana11.html.

Gant, D.B. and Gant, J.P., 2002. Enhancing e-service delivery. E-government series. Delivering and financing e-service. Lanham: Pricewaterhouse Coopers Endowment.

Hernes, T., 2005. Four ideal-type organizational responses to NPM reforms and some consequences. International Review of Administrative Sciences, 71 (1), 5-17.

Ho, A. and Ni, A.N., 2004. Explaining the adoption of e-government features. A case study of Iowa County Treasurers' Office. American Review of Public Administration, 34 (2), 164-180.

Holden, S.H., Norris, D.F. and Fletcher, P.D., 2003. Electronic government at the local level. Progress to date and future issues. Public Performance and Management Review, 26 (4), 325-344.

Holzer, M., Hu, L.-T. and Song, S.-H., 2004. Digital government and citizen participation in the United States. In: A. Pavlichev and G.D. Garson, eds. Digital government: principles and best practices. Hershey, PA: Idea Group Publishing, 306-319.

Homburg, V. and Bekkers, V., 2005. E-government and NPM: a perfect marriage? In: $\mathrm{V}$. Bekkers and V. Homburg, eds. The information ecology of e-government. Amsterdam: IOS Press, 155-170.

Hughes, O.E. 2003. Public management and administration: an introduction. Gordonsville: Palgrave Macmillan.

Jaeger, P.T., 2005. Deliberative democracy and the conceptual foundations of electronic government. Government Information Quarterly, 22 (4), 702-719.

Justice, J.B., Melitsky, J. and Smith, D.L., 2006. E-government as an instrument of fiscal accountability and responsiveness. Do the best practitioners employ the best practices? American Review of Public Administration, 36 (3), 301-332.

Keating, M., 2001. Public management reform and economic and social development. OECD Journal on Budgeting, 1 (2), 141-212.

Kernaghan, K., 2005. Moving towards the virtual state: integrating services and service channels for citizen centred delivery. International Review of Administrative Sciences, 71 (1), 119-131.

Koppell, J.G.S., 2005. Pathologies of accountability: ICANN and the challenge of multiple accountabilities disorder. Public Administration Review, 65 (1), 94-108.

Marche, S. and McNiven, J.D., 2003. E-government and e-governance: the future isn't what it used to be. Canadian Journal of Administrative Sciences, 20 (1), pp. 74-86.

Matheson, A., 2004. Modernising government: the synthesis. Available from: http://www. vuw.ac.nz.

Michel, H., 2005. E-administration, e-government, e-governance and the learning city: a typology of citizenship managing using ICT's. The Electronic Journal of E-Government, 3 (4), 213-218.

Ministry for Public Administrations, 2009. IRIA report. Madrid: Ministry for Public Administrations.

Moon, M.J., 2002. The evolution of e-government among municipalities: rhetoric or reality? Public Administration Review, 62 (4), 424-433.

Moon, M.J., 2003. Can IT help government to restore public trust? Declining public trust and potential prospects of IT in the public sector. 36th Hawaii International Conference on System Sciences.

Musso, J., Weare, C. and Hale, M., 2000. Designing web technologies for local governance reform: good management or good democracy? Political Communication, 17 (1), 1-19.

Norris, D., 2007. Current issues and trends in e-government research. Hershey: Cybertech Pub. Norris, D., 2008. E-government research: policy and management. Baltimore: IGI Publishing. OECD, 2003. The e-government imperatives: main findings. Paris: OECD. 
Pollit, C., 2000. Is the emperor in his underwear? An analysis of the impacts of public management reform. Public Management, 2 (2), 181-199.

Pollit, C. and Bouckaert, G., 2000. Public management reform. A comparative analysis. Oxford: Oxford University Press.

Reddick, C.G., 2004. A two-stage model of e-government growth: theories and empirical evidence for US cities. Government Information Quarterly, 21 (1), 51-64.

Reddick, C.G., 2009. Strategies for local e-government adoption and implementation, 2 vols. Baltimore: IGI Publishing.

Rogers, E.M., 1983. Diffusion of innovations. New York: Free Press.

Roy, J., 2005. Service, security, transparence and trust: government on-line or governance renewal in Canada. International Journal of Electronic Government Research, 1 (1), 40-58.

Roy, J., 2006. E-government in Canada. Ottawa: University of Ottawa Press.

Royo, S., 2008. El gobierno electrónico en la rendición de cuentas de la administración local. Madrid: Instituto de Estudios Fiscales.

Ruano, José M., 2006. Nowe technologie informatycne w administracji publicznej. Sluzba Cywilna, no. 13. Warsaw, 15-29.

Saxena, K.B.C., 2005. Towards excellence in e-government. International Journal of Public Sector Management, 18 (6), 498-513.

Siau, K. and Long, Y., 2005. Synthesizing e-government stage models. A meta synthesis based on a meta-ethnography approach. Industrial Management and Data Systems, 105 (4), 443-458.

Tambouris, E., Gorilas, S. and Boukis, G., 2001. Investigation of electronic government. Panhellenic Informatic Conference, Cyprus.

Thomas, J.C. and Streib, G., 2005. E-democracy, e-commerce and e-research. Examining the electronic ties between citizens and governments. Administration and Society, 63 (3), 259280.

Torres, L., 2004. Reshaping public administration: the Spanish experience compared to the UK. Public Administration, 82 (2), 445-464.

Travers, T., Jones, G. and Burnham, J., 1993. The impact of population size on local authority costs and effectiveness. York: Joseph Rowntree Foundation.

Weare, C., Musso, J.A. and Hale, M.L., 1999. Electronic democracy and the diffusion of municipal web pages in California. Administration and Society, 31 (1), 3-27.

West, D.M., 2004. E-government and the transformation of service delivery and citizen attitudes. Public Administration Review, 64 (1), 15-27.

West, D.M., 2005. Digital government: technology and public sector performance. Princeton, NJ: Princeton University Press.

Wimmer, M., 2003. E-government services in the future. Report on the JANUS Workshop Progressing the Information Society: The Role of Government. Brussels.

Wimmer, M., 2007. Electronic government. Berlin-Heidelberg: Springer Verlag. 